The position of the infrared source IRS 16 in the Galactic Center region relative to a visual field star

G. Neugebauer, K. Matthews, and B. T. Soifer

Citation: AIP Conference Proceedings 83, 107 (1982); doi: 10.1063/1.33497

View online: http://dx.doi.org/10.1063/1.33497

View Table of Contents: http://aip.scitation.org/toc/apc/83/1

Published by the American Institute of Physics 


\section{THE POSITION OF THE INFRARED SOURCE IRS 16 \\ IN THE GALACTIC CENTER REGION RELATTVE TO A VISUAL FIELD STAR}

G. Neugebauer, K. Matthews, and B. T. Soifer

Palomar Observatory, California Institute of Technology. Pasadena, CA 91125

The position of IRS 16 was measured with respect to the visual star whose position is approximately

$$
\alpha(1850)=17^{h} 42^{m} 30^{\circ} .0, \quad \delta(1950)=-28^{\circ} 59^{\prime} 01^{\prime \prime}
$$

on 1981 July 25 UT and 1981 Sep 1 UT using the $5 \mathrm{~m}$ Hale Telescope of Palomar Observatory. Although the source IRS 16 was observed at $2.2 \mu \mathrm{m}$, the visual star could not be isolated at $2 \mu \mathrm{m}$ because of confusing sources in its neighborhood.

For this reason, an indirect measuring technique was used. Initially the position in the visual guide field corresponding to the center of the $2.2 \mu \mathrm{m}$ diaphragm was determined using a nearly bright star: the $2.2 \mu \mathrm{m}$ diaphragm was $1.5^{\prime \prime}$ in diameter. The telescope was then pointed to the Galactic Center and the $2.2 \mu \mathrm{m}$ diaphragm centered on the infrared flux from IRS 16. Simultaneously the position of the visual star near IRS 16 was marked in the visual guide field. The telescope was then moved to make the image of the visual star coincide with the previously marked position of the $2.2 \mu \mathrm{m}$ diaphragm. This motion. corresponding to the separation of the visual stars and the $2.2 \mu \mathrm{m}$ position of IRS 16 was measured on the telescope differential encoders. The telescope was returned to IRS 16, the motion recorded, and the procedure repeated.

In two nights, 18 movements were recorded; the average displacements of IRS 16 from the visual star were:

$$
\Delta \alpha=-7.9^{\prime \prime}, \quad \Delta \delta=-18.2^{\prime \prime}
$$

The statistical uncertainties in the average displacements based on the deviations in the 18 measurements made in both nights are $1 \sigma=0.1 "$. The systematic errors, which dominate the uncertainties, are harder to assess, but are probably less than or on the order of $0.5^{\prime \prime}$.

In comparison, Becklin and Neugebauer ${ }^{1}$ find

$$
\Delta \alpha=-9.1^{\prime \prime} \quad \Delta \delta=16.3^{\prime \prime}
$$

with uncertainties of $1.5^{\prime \prime}$; the observations thus formally agree within their uncertainties.

The displacements between the visual star and the two sources found in the CCD trames by Biretto, Lo and Young ${ }^{2}$ are:

$$
\begin{array}{ccc}
\text { source } A & \Delta \alpha=-8.7^{\prime \prime} \pm 0.1^{\prime \prime} & \Delta \delta=-16.1 \pm 0.1^{\prime \prime} \\
\text { source } B & \Delta \alpha=-8.6^{\prime \prime} \pm 0.1^{\prime \prime} & \Delta \delta=-13.8^{\prime \prime} \pm 0.1^{\prime \prime}
\end{array}
$$

The position of IRS 16 as determined in the present observations thus differs from that of both sources, although the differences between IRS 16 and source A is less clear given the uncertain nature of the systematic errors.

It is of interest to know if IRS 16 would be expected to have been detected at $0.9 \mu \mathrm{m}$. Becklin et al ${ }^{3}$ find that the dereddened magnitudes for IRS 16 are $\mathrm{K}(2.2 \mu \mathrm{m})=5.6 \pm 0.2$ and $\mathrm{H}(1.65 \mu \mathrm{m})=5.7 \pm 0.2 \mathrm{mag}$. A measurement of the colors of IRS 16 with a 1.5" diameter diaphragm and a north south chop $4^{\prime \prime}$ in length indicates the dereddened magnitude of IRS 16 at $1.25 \mu \mathrm{m}$ in a $3.8^{\prime \prime}$ 
diaphragm would be $J=6.4 \pm 0.3 \mathrm{mag}$. It is thus reasonable that the intrinsic magnitude of IRS 16 at $0.9 \mu \mathrm{m}$ would be between 6 and 8 . The extinction at 0.9 $\mu \mathrm{m}$ corresponding to $\mathrm{A}_{\mathrm{F}}=30 \mathrm{mag}$ is approximately $13 \mathrm{mag}$. If the $0.9 \mu \mathrm{m}$ magnitude of IRS 16 is $6 \mathrm{mag}$, it would easily have been seen in the CCD frames while if it were as faint as $8 \mathrm{mag}$ it would, as an extended source, be only marginally detectable. The identification of the sources seen in the CCD frames with IRS16 is thus still unresolved.

We thank J. Carrasco, S. E. Persson, J. Lacy, and K. Y. Lo for assistance in this work and many discussions. This work was supported by grants from NSF and NASA.

\section{REFERENCES}

1. Becklin, E. E. and Neugebauer, G., Ap. J. (Letters), 200, L7 (1975).

2. Biretta, J., Lo, K. Y., and Young, P. J., (This volume).

3. Becklin, E. E., Matthews, K., Neugebauer, G. and Willner, S. P., Ap. J., 219, 118 (1978). 